\title{
Parâmetros nutricionais de novilhas Nelore em pastejo de capim marandu recebendo suplemento energético, proteico e múltiplo no período de transição seca-águas ${ }^{1}$
}

\section{Nutritional parameters of Nellore heifers grazing in grass marandu receiving energy, protein and multiple supplement the dry-rainy transition period}

\author{
Lilian Chambó Rondena Pesqueira-Silva ${ }^{2 *}$; Joanis Tilemahos Zervoudakis ${ }^{3}$; \\ Claúdio Vieira de Araújo $^{3}$; Luciano da Silva Cabral $^{3}$; \\ Luciana Keiko Hatamoto-Zervoudakis ${ }^{3}$; André Alves de Oliveira ${ }^{4}$; \\ Renata Pereira da Silva-Marques ${ }^{2}$
}

\section{Resumo}

O objetivo foi avaliar o consumo e a digestibilidade dos nutrientes, a concentração de nitrogênio amoniacal $\left(\mathrm{N}_{-} \mathrm{NH}_{3}\right)$ no rúmen e nitrogênio ureico no soro (NUS) em novilhas Nelore recriadas em capim Marandu durante o período de transição seca-águas recebendo suplementos concentrados. Foram utilizadas quatro novilhas Nelore com peso corporal e idade inicial média de $189,5 \mathrm{~kg}$ e 12 meses, respectivamente, distribuídas em quatro piquetes de 0,25 ha cada. O delineamento utilizado foi o quadrado latino (quatro suplementos e quatro períodos de 14 dias). Os suplementos avaliados foram: suplemento energético (SE), proteico (SP) e múltiplo (SM), fornecidos na quantidade de $1 \mathrm{~kg}$ animal dia $^{-1}$, além do suplemento contendo mistura mineral comercial ad libitum (MM). A suplementação concentrada não influenciou os consumos de matéria seca, de matéria orgânica total e da forragem. $\mathrm{O}$ suplemento SP proporcionou maior $(\mathrm{P}<0,0001)$ consumo de proteína bruta $(\mathrm{PB})$. Os suplementos $\mathrm{SE}$ e SP resultaram em maior consumo de extrato etéreo. A digestibilidade da $\mathrm{PB}$ foi maior $(\mathrm{P}<0,0001)$ para os animais suplementados com SP e SM. Imediatamente antes e quatro horas após o fornecimento da suplementação observaram-se maiores concentrações de $\mathrm{N}^{-N_{3}}$ ruminal para os suplementos SP e SM. Não verificou-se diferença quanto ao nitrogênio uréico no soro (NUS). A utilização de suplemento proteico e múltipo proporcionaram melhor adequação do ambiente ruminal de novilhas no período de transição seca-águas alimentadas com capim Marandu.

Palavras-chave: Amônia ruminal, consumo, digestibilidade, suplementação

\footnotetext{
${ }^{1}$ Parte da Dissertação de Mestrado em Ciência Animal, da primeira autora, Universidade Federal de Mato Grosso, UFMT, Cuiabá, MT.

2 Discentes de Doutorado em Ciência Animal, UFMT, Cuiabá, MT. E-mail: lilianrondena@hotmail.com; renatinharps@hotmail. com

3 Profs., Universidade Federal de Mato Grosso, UFMT, Cuiabá, MT. E-mail: joanisz@yahoo.com.br; araujocv@bol.com.br; lucianoufmt@gmail.com; lukeiko@yahoo.com.br

${ }^{4}$ Dr. em Zootecnia, Universidade Estadual Paulista "Júlio de Mesquita Filho”, UNESP, Jaboticabal, SP. E-mail: andrezoo07@ yahoo.com.br

* Autor para correspondência
} 


\begin{abstract}
The objective was to evaluate thein take and digestibility of nutrients, ammonia nitrogen (NH3-N) in the rumen and serum urea nitrogen (BUN) in Nellore heifers in grass Marandu recreated during the transition period dry energy supplement receiving waters, protein and multiple. We used four heifers with average body weight and initial age of $189.5 \mathrm{~kg}$ and 12 months respectively, distributed in four paddocks of 0.25 ha each. The design was a $4 \times 4$ Latin square (four supplements and four periods of 14 days). The supplements were: energy supplement (ES) protein (PS) and multiple (MS), provided the amount of 1 $\mathrm{kg}$ animal day $^{-1}$ in addition to supplement containing commercial mineral mixture ad libitum (MM). The concentrate supplementation did not increase intakes of dry matter, total organic matter and forage. The additional SP provided greater $(\mathrm{P}<0,0001)$ intake of crude protein $(\mathrm{CP})$. The SE and SP supplement resulted ingreater ether extract intake. The $\mathrm{CP}$ was higher $(\mathrm{P}<0.0001)$ in animals supplemented with SP and SM. Immediately before and four hours after supplementation higher concentrations of ruminal NH3-N were observed for the SM and SP supplements. There were no differences for ser um urea nitrogen (BUN). The use of protein supplement and multiple provided the best fit of the rumen of heifers during the transition period dry-rainy fed on grasses Marandu environment.
\end{abstract}

Key words: Digestibility, intake, ruminal ammonia, suplementation

\section{Introdução}

Para que a produtividade e a sustentabilidade do sistema de produção não sejam comprometidos devido às imposições climáticas e ambientais, à suplementação de bovinos em pastejo é uma alternativa para fornecer nutrientes limitantes na forragem principalmente no período seco do ano, pois segundo Silva-Marques et al. (2015a, 2015b), essa estratégia pode refletir em mudanças no consumo de forragem, maior disponibilidade de nutrientes e energia dietética, resultando em maior desempenho animal e retorno econômico.

Apesar do período seco do ano ser o gargalo da produção de bovinos em pastejo, no período de transição seca-águas verifica-se o aparecimento de rebrotas nos pastos e como consequência dos níveis elevados de compostos nitrogenados não-proteicos e/ou dos níveis reduzidos de energia de rápida disponibilidade ruminal na gramínea pastejada, desta forma, pode-se ocorrer baixo aproveitamento dos compostos nitrogenados, como resultado de sua baixa conversão em proteína microbiana (SAMPAIO et al., 2010).

Nestas condições, os animais podem responder ao aumento no fornecimento de proteína de forma direta com utilização de suplementos proteicos, ou indireta, pela utilização de suplementos energéticos, os quais ampliam a síntese de compostos nitrogenados microbianos a partir do nitrogênio da forragem (BARROS et al., 2014).

Assim, objetivou-se avaliar o fornecimento de suplemento energético, proteico e múltiplo sobre o consumo e a digestibilidade dos nutrientes, a concentração de nitrogênio amoniacal $\left(\mathrm{N}_{-} \mathrm{NH}_{3}\right)$ no rúmen e nitrogênio ureico no soro (NUS) de novilhas na fase de recria sob pastejo em Brachiaria brizantha cv. Marandu no período de transição seca-águas.

\section{Material e Métodos}

O experimento foi conduzido no Setor de Bovinocultura de Corte da Fazenda Experimental da Faculdade de Agronomia, Medicina Veterinária e Zootecnia da Universidade Federal de Mato Grosso, localizada no município de Santo Antônio do Leverger - MT, durante o período de transição secaáguas, entre os meses de agosto a outubro de 2010.

Foram utilizadas quatro novilhas nelores com peso corporal (PC) médio inicial de 189,5 \pm 2,87 kg e idade média de 12 meses, distribuídas individualmente em uma área com quatro piquetes de 0,25 ha cada, formados com Brachiaria brizanha cv. Marandu, providos de bebedouros e cochos cobertos para fornecimento do suplemento. 
Foram avaliados quatro suplementos, sendo: MM: mistura mineral (controle); SE: suplemento energético; SP: suplemento proteico e SM: suplemento múltiplo (Tabela 1). Os suplementos foram fornecidos na quantidade de $1 \mathrm{~kg}$ animal $\mathrm{dia}^{-1}$, (exceto MM que foi ad libitum) na matéria natural, às 10:00 horas da manhã.
O delineamento experimental utilizado foi o quadrado latino $4 \times 4$ com quatro suplementos e quatro períodos experimentais de 14 dias cada, perfazendo um total de 56 dias. Os primeiros nove dias de cada período experimental foram destinados à adaptação dos animais aos suplementos e à amostragem da forragem.

Tabela 1. Composição dos suplementos em $\mathrm{g} / \mathrm{kg}$ com base na matéria seca.

\begin{tabular}{lcccc}
\hline \multirow{2}{*}{ Ingrediente $^{1}$} & \multicolumn{4}{c}{ Suplemento } \\
\cline { 2 - 5 } & $\mathrm{MM}^{2}$ & $\mathrm{SE}^{3}$ & $\mathrm{SP}^{4}$ & $\mathrm{SM}^{5}$ \\
\hline Farelo de soja & - & 80,0 & 820,0 & 460,0 \\
Milho grão moído & - & 840,0 & 100,0 & 460,0 \\
Uréia:Sulfato de amônio (9:1) $_{\text {Mistura mineral completa }^{2}}$ & - & 20,0 & 20,0 & 20,0 \\
\hline
\end{tabular}

${ }^{1}\left(\mathrm{~g} / \mathrm{kg}\right.$ de matéria seca); ${ }^{2}$ mistura mineral comercial; ${ }^{3} \mathrm{SE}$ : suplemento energético; ${ }^{4} \mathrm{SP}$ : suplemento proteico e ${ }^{5} \mathrm{SM}$ : suplemento múltiplo.

Fonte: Elaborado pelos autores.

No primeiro dia de cada período experimental (a cada 14 dias), realizou-se a coleta de amostras da forragem nos diferentes piquetes por meio do corte, a cinco $\mathrm{cm}$ do solo, de dez áreas delimitadas por um quadrado metálico de $0,5 \times 0,5 \mathrm{~m}$, escolhidas aleatoriamente em cada piquete experimental, para estimar a massa de forragem $\left(\mathrm{kg} \mathrm{ha}^{-1}\right)$.

Após a pesagem das amostras de forragem, foi feita homogeneização das amostras por piquete e dessas retiradas duas amostras compostas, uma para determinação da massa de forragem (MF) e outra para determinação do percentual das frações folha verde, folha seca, colmo verde e colmo seco. Para a avaliação da forragem ingerida pelos animais foi utilizada a técnica da simulação manual de pastejo. Das amostras destinadas à estimativa da MF foi calculado o percentual de matéria seca potencialmente digestível (MSpD), segundo Paulino et al. (2004).

Para estimativa da excreção de matéria seca (MS) fecal, utilizaram-se $10 \mathrm{~g}$ de óxido crômico diariamente, acondicionados em cartucho de papel e introduzido diretamente no rúmen via sonda oreosofágica às $11 \mathrm{~h}$ do $3^{\circ}$ ao $11^{\circ}$ dia de cada período experimental. Posteriormente, realizaram-se três coletas de amostra de fezes diretamente do reto: no $10^{\circ}$ dia às $16 \mathrm{~h}$; no $11^{\circ}$ dia às $12 \mathrm{~h}$; e no $12^{\circ}$ dia às $8 \mathrm{~h}$. Após a coleta, as amostras de fezes foram acondicionadas em sacos plásticos, identificadas e congeladas $\mathrm{a}-10^{\circ} \mathrm{C}$.

As amostras de fezes e de forragem foram présecas em estufa com ventilação forçada a $60^{\circ} \mathrm{C}$ por 72 horas e moídas em moinho de facas com peneira com crivos de 1,0 mm. Das amostras de fezes, formou-se uma amostra composta por animal e por período, as quais foram armazenadas em frascos de plásticos identificados para posteriores análises.

A estimativa da excreção de MS fecal foi realizada considerando-se a razão entre a quantidade de indicador fornecido e sua concentração nas fezes: Excreção fecal $=[$ Quantidade de cromo fornecida $(\mathrm{g})$ /concentração de cromo nas fezes ( $\mathrm{g} / \mathrm{kg}$ MS fecal)].

A fibra em detergente neutro indigerível (FDNi) foi utilizada como indicador da digestibilidade da dieta. A concentração de FDNi foi determinada nas 
amostras de pastejo simulado, suplementos e fezes por intermédio da incubação in situ por 240 horas, segundo Casali et al. (2008). Após este período, o material remanescente da incubação foi submetido à extração com solução detergente neutra para quantificação dos teores de FDNi.

As estimativas do consumo voluntário foram obtidas empregando-se a equação: $\mathrm{CMS}=\{[(\mathrm{EF} \times$ CIF) - IS] / CIFO \} + CMSS em que CMS (kg/dia) = consumo de matéria seca; $\mathrm{EF}=$ excreção fecal $(\mathrm{kg} / \mathrm{dia}) ; \mathrm{CIF}=$ concentração do indicador nas fezes $(\mathrm{kg} / \mathrm{kg})$; IS = indicador presente no suplemento $(\mathrm{kg} / \mathrm{dia}) ; \mathrm{CIFO}=$ concentração do indicador na forragem $(\mathrm{kg} / \mathrm{kg})$ e CMSS = consumo de matéria seca de suplemento ( $\mathrm{kg} / \mathrm{dia})$.

Quatro horas após o fornecimento do suplemento, realizaram-se as coletas de sangue por punção da veia caudal no $13^{\circ}$ dia de cada período experimental. As amostras foram centrifugadas a $4000 \mathrm{~g}$ por 15 minutos, obtendo-se o soro sanguíneo que foi armazenado a $-15^{\circ} \mathrm{C}$ para posterior quantificação dos teores de uréia (VALADARES et al., 1999). As concentrações de uréia foram estimadas no soro sangüíneo utilizando-se kits comerciais (Labtest). A conversão dos valores de uréia em nitrogênio ureico foi realizada pela multiplicação dos valores obtidos pelo fator 0,466 .

Para avaliação da concentração do nitrogênio amoniacal $\left(\mathrm{N}-\mathrm{NH}_{3}\right)$ ruminal, realizaram-se coletas de líquido ruminal (via sonda oreosofágica) imediatamente antes (0) e 4 horas após o fornecimento da dieta. Uma alíquota de $40 \mathrm{~mL}$ foi adicionada de $1 \mathrm{~mL}$ de ácido sulfúrico $\left(\mathrm{H}_{2} \mathrm{SO}_{4}\right)$ (1:1), acondicionada em frasco plástico, identificada e congelada a $-15^{\circ} \mathrm{C}$, para posterior quantificação da concentração do $\mathrm{N}^{-\mathrm{NH}_{3}}$ ruminal por intermédio do sistema micro-Kjeldahl, sem digestão ácida e utilizando-se como base para destilação o hidróxido de potássio $(2 \mathrm{~N})$.

As amostras de forragem, fezes e suplementos foram analisadas para determinação da matéria seca (MS), matéria orgânica (MO), proteína bruta (PB), extrato etéreo (EE), matéria mineral (MM), fibra em detergente neutro (FDN), fibra em detergente neutro corrigida para cinzas e proteína (FDNcp) e fibra em detergente ácido (FDA) de acordo com as metodologias propostas por Silva e Queiroz (2002). A determinação do nitrogênio insolúvel em solução detergente neutra (NIDN) e ácida (NIDA) foi realizada conforme Van Soest, Robertson e Lewis (1991).

A quantificação dos carboidratos totais (CT) foi obtida pela equação proposta por Sniffen et al. (1992): $\quad \mathrm{CT}=100-(\% \mathrm{~PB}+\% \mathrm{EE}+\% \mathrm{MM})$. Os carboidratos não fibrosos (CNF) dos suplementos foram estimados de acordo com adaptação de Hall (2000), em virtude da inclusão da uréia na composição dos suplementos, sendo: $\mathrm{CNF}=100$ $[(\% \mathrm{~PB}-\% \mathrm{~PB}$ da ureia $+\%$ ureia $)+\% \mathrm{FDN}+\% \mathrm{EE}$ $+\%$ cinzas]. Com base na composição química dos alimentos, os teores de nutrientes digestíveis totais (NDT) foram estimados segundo o NRC (2001): NDT $(\%)=($ PBD + CNFD + FDNpD + EED x 2,25) - 7; sendo a constante 7 o valor metabólico fecal. Os valores de proteína bruta digestível (PBD), ácidos graxos digestíveis (AGD), fibra em detergente neutro corrigida para proteína digestível (FDNpD) e carboidratos não fibrosos digestíveis (CNFD) foram estimados de acordo com as seguintes equações:

$\operatorname{PBD}($ volumosos $)=\mathrm{PB} \times \operatorname{EXP}(-1,2 \times \mathrm{PIDA} / \mathrm{PB})$;

PBD $($ concentrados $)=$ PB x [1- $(0,4 \times$ PIDA/PB $)$; $\mathrm{EED}=(\mathrm{EE}-1) ; \mathrm{CNFD}=(0,98 \times \mathrm{CNF} \times \mathrm{PAF}) ;$

$\mathrm{FDNpD}=0,75 \times(\mathrm{FDNp}-\mathrm{L}) \times\left[1-(\mathrm{L} / \mathrm{FDNp})^{0,667}\right]$. Em que: PIDA - proteína insolúvel em detergente ácido; PAF - fator de ajuste para processamento físico; L - lignina; FDNp - FDN corrigida para proteína.

As variáveis relacionadas com os suplementos foram submetidas à análise de variância, e as comparações entre os períodos e os suplementos foram realizadas pelo teste de médias StudentsNewman-Keulls (SNK), por meio do procedimento GLM do sistema estatístico SAS (1999), a 5\% de significância. A variável $\mathrm{N}_{-} \mathrm{NH}_{3}$ ruminal foi analisada num esquema de parcelas subdivididas, 
em que os suplementos constituíram as parcelas, e os tempos de coleta as subparcelas.

\section{Resultados e Discussão}

Os valores médios de massa de forragem (MF), matéria seca potencialmente digestível (MSpD), folha verde (MSFV), folha seca (MSFS), colmo verde (MSCV) e colmo seco (MSCS) durante o experimento foram de $4.058 ; 2.880 ; 929 ; 693$; $1.024 ; 1.446 \mathrm{~kg}$ de $\mathrm{MS} / \mathrm{ha}$, respectivamente (Tabela 2).

Tabela 2. Valores médios em $\mathrm{Kg} /$ ha para massa de forragem (MF), matéria seca potencialmente disgestível (MSpD), folha verde (MSFV); folha seca (MSFS), colmo verde (MSCV) e colmo seco (MSCS), nos meses experimentais.

\begin{tabular}{lccc}
\hline Variável & Agosto & Setembro & Outubro \\
\hline MF & 4302,10 & 3954,80 & 3916,55 \\
MSpD & 3002,87 & 2778,25 & 2859,86 \\
MSFV & 1035,50 & 833,55 & 919,40 \\
MSFS & 599,85 & 800,65 & 677,75 \\
MSCV & 942,00 & 1104,50 & 1024,00 \\
MSCS & 1724,50 & 1216,00 & 1397,35 \\
\hline
\end{tabular}

Fonte: Elaborado pelos autores.

A MF e MSpD (71,02\%) não limitaram o consumo de forragem dos animais. Além da massa de forragem, a oferta média de MSpD foi de $11 \mathrm{~kg}$ $/ 100 \mathrm{~kg}$ de PC por animal.dia ${ }^{-1}$ (Tabela 2) o que permitiu seletividade aos animais ao pastejarem.

O teor médio de proteína bruta (PB) na forragem disponível ao pastejo animal obtida via simulação manual do pastejo foi de 7,73 \% (Tabela 3), valor este acima de 7,0\% de PB na dieta basal, considerado como nível crítico para satisfazer os requisitos microbianos em compostos nitrogenados (LAZZARINI et al., 2009), consequentemente garantir a fermentação dos carboidratos fibrosos no rúmen.

Com base nos valores médios de PB, fibra em detergente neutro (FDN), nitrogênio insolúvel em detergente neutro (NIDN), nitrogênio insolúvel em detergente ácido (NIDA) da forragem (Tabela 3) e considerando o período de transição seca-águas podese classificar a forragem ingerida pelos animais como de média qualidade (COSTA et al., 2009; SAMPAIO et al., 2010; DETMANN et al., 2011).

As estratégias de suplementação não promoveram incrementos sobre os consumos de matéria seca total (MS), MS da forragem, matéria orgânica (MO) total e MO da forragem (Tabela 4), não havendo portanto, diferenças no consumo de novilhas recebendo suplementação concentrada em relação aquelas recebendo apenas mistura mineral (MM). Os consumos de MS total, MS da forragem e fibra em detergente neutro (FDN) pelos animais que receberam suplemento, expressos em \% dopeso corporal (PC) também não foram alterados relação àqueles que consumiram apenas MM (Tabela 4).

Segundo Herd (1997) a suplementação concentrada de até $0,3 \%$ do PC proporciona efeito aditivo. No entanto, para níveis de suplementação entre $0,3 \%$ a $1 \%$ do PC há uma redução no consumo de matéria seca da forragem em $300 \mathrm{~g}$ para cada $500 \mathrm{~g}$ de suplemento ingerido. Diferente dos dados observados por Herd (1997), a suplementação concentrada no nível de $0,46 \%$ do PC não interferiu no consumo de forragem das novilhas. Este fato pode ser explicado pela disponibilidade e qualidade da forragem ingerida pelos animais, a qual proporcionou os animais seletividade ao pastejarem. 
Tabela 3. Composição bromatológica da forragem e dos suplementos energético (SE) proteico (SP) e múltiplo (SM), com base na matéria seca.

\begin{tabular}{lcccc}
\hline \multirow{2}{*}{ Variável } & \multicolumn{3}{c}{ Suplemento } & \multirow{2}{*}{ B. $_{\text {brizantha }}$} \\
\cline { 2 - 4 } & SE & SP & SM & \\
\hline Matéria seca $^{2}$ & 919,1 & 925,8 & 909,6 & 350,8 \\
Matéria mineral $^{3}$ & 75,3 & 96,4 & 108,1 & 79,5 \\
Matéria orgânica $^{3}$ & 924,7 & 903,6 & 891,9 & 920,5 \\
Proteína bruta $^{3}$ & 179,1 & 475,9 & 356,9 & 77,3 \\
Extrato etéreo $^{3}$ & 22,8 & 18,2 & 12,7 & 21,6 \\
Carboidratos totais $^{3}$ & 722,7 & 409,5 & 522,3 & 821,5 \\
Fibra em detergente neutro $^{3}$ & 115,1 & 132,1 & 112,4 & 682,6 \\
Fibra em detergente ácido $^{3}$ & 29,2 & 46,6 & 31,1 & 336,6 \\
FDN corrigida cinzas e proteína $^{3}$ & 108,6 & 125,0 & 105,9 & 626,4 \\
FDN indigerível $^{3}$ & 25,1 & 32,6 & 35,9 & 202,1 \\
Nitrogênio insolúvel em detergente neutro $^{4}$ & 29,5 & 12,2 & 14,7 & 301,3 \\
Nitrogênio insolúvel em detergente ácido $^{4}$ & 21,4 & 25,5 & 35,3 & 96,5 \\
Carboidratos não fibrosos $^{3}$ & 646,7 & 317,1 & 449,1 & 195,2 \\
Nutrientes digestíveis totais $^{3,5}$ & 821,1 & 790,2 & 772,9 & 529,5 \\
\hline
\end{tabular}

${ }^{1}$ Simulação pastejo; ${ }^{2}(\mathrm{~g} / \mathrm{kg}) ;{ }^{3}\left(\mathrm{~g} / \mathrm{kg}\right.$ matéria seca); ${ }^{4}\left(\mathrm{~g} / \mathrm{kg}\right.$ de nitrogênio total); ${ }^{5}$ Estimado segundo NRC (2001): NDT $(\%)=($ PBD + CNFD +FDNpD + EED x 2,25) - 7 .

Fonte: Elaborado pelos autores.

Tabela 4. Consumo de nutrientes dos suplementos e da forragem em novilhas sob pastejo recebendo suplemento mineral (MM), energético (SE), proteico (SP) e múltiplo (SM) no período de transição seca-águas.

\begin{tabular}{|c|c|c|c|c|c|}
\hline \multirow{2}{*}{ Variável } & \multicolumn{4}{|c|}{ Suplemento } & \multirow[t]{2}{*}{ Valor P } \\
\hline & MM & SE & SP & SM & \\
\hline & \multicolumn{4}{|c|}{$\mathrm{kg} / \mathrm{animal} / \mathrm{dia}$} & \\
\hline Matéria seca total & $3,57 \pm 0,58$ & $4,34 \pm 0,45$ & $4,59 \pm 0,98$ & $4,35 \pm 0,46$ & 0,0643 \\
\hline Matéria seca de forragem & $3,57 \pm 0,58$ & $3,42 \pm 0,45$ & $3,67 \pm 0,98$ & $3,44 \pm 0,46$ & 0,9466 \\
\hline Matéria orgânica (MO) & $6,07 \pm 1,29$ & $5,92 \pm 1,57$ & $6,17 \pm 2,14$ & $5,94 \pm 1,36$ & 0,8812 \\
\hline MO de forragem & $3,29 \pm 0,53$ & $3,14 \pm 0,41$ & $3,37 \pm 0,91$ & $3,16 \pm 0,42$ & 0,9466 \\
\hline Proteína bruta & $0,23 \pm 0,03^{\mathrm{d}}$ & $0,39 \pm 0,03^{\mathrm{c}}$ & $0,68 \pm 0,06^{\mathrm{a}}$ & $0,55 \pm 0,03^{\mathrm{b}}$ & $<0,0001$ \\
\hline Extrato etéreo & $0,05 \pm 0,01^{\mathrm{b}}$ & $0,07 \pm 0,01^{\mathrm{a}}$ & $0,07 \pm 0,01^{\mathrm{a}}$ & $0,06 \pm 0,01^{\mathrm{ab}}$ & 0,0404 \\
\hline Fibra em detergente neutro (FDN) & $2,50 \pm 0,41$ & $2,50 \pm 0,31$ & $2,69 \pm 0,69$ & $2,50 \pm 0,32$ & 0,9190 \\
\hline FDN indigerível & $0,68 \pm 0,11$ & $0,67 \pm 0,08$ & $0,73 \pm 0,18$ & $0,69 \pm 0,09$ & 0,9237 \\
\hline Carboidratos totais & $3,00 \pm 0,49$ & $3,54 \pm 0,38$ & $3,46 \pm 0,83$ & $3,36 \pm 0,38$ & 0,3735 \\
\hline Carboidrato não-fibroso & $0,77 \pm 0,13^{\mathrm{c}}$ & $1,33 \pm 0,09^{\mathrm{a}}$ & $1,08 \pm 0,21^{\mathrm{b}}$ & $1,15 \pm 0,10^{\mathrm{ab}}$ & 0,0020 \\
\hline \multirow[t]{2}{*}{ Nutrientes digestíveis totais ${ }^{1}$} & $1,93 \pm 0,31^{\mathrm{b}}$ & $2,60 \pm 0,24^{\mathrm{a}}$ & $2,71 \pm 0,53^{\mathrm{a}}$ & $2,56 \pm 0,25^{\mathrm{a}}$ & 0,0106 \\
\hline & \multicolumn{4}{|c|}{ \% do Peso corporal } & \\
\hline Matéria seca total & $1,65 \pm 0,13$ & $1,99 \pm 0,08$ & $2,10 \pm 0,20$ & $1,96 \pm 0,10$ & 0,0709 \\
\hline Matéria seca de forragem & $1,65 \pm 0,13$ & $1,57 \pm 0,08$ & $1,68 \pm 0,20$ & $1,58 \pm 0,11$ & 0,9364 \\
\hline Fibra em detergente neutro & $1,15 \pm 0,09$ & $1,14 \pm 0,06$ & $1,23 \pm 0,14$ & $1,15 \pm 0,08$ & 0,9087 \\
\hline
\end{tabular}

Valores seguidos de letras iguais na linha, não diferem pelo teste SNK a 5\% de probabilidade.

${ }^{1}$ Estimado segundo NRC (2001): NDT $(\%)=(\mathrm{PBD}+\mathrm{CNFD}+\mathrm{FDNpD}+\mathrm{EED} \times 2,25)-7$.

Fonte: Elaborado pelos autores. 
Pode-se verificar maior consumo de PB $(\mathrm{P}<0,0001)$ para os animais que receberam o suplemento proteico (SP), já o menor consumo de PB foi observado para os animais que receberam apenas MM. Estes resultados já eram esperados, uma vez que, o suplemento SP apresenta em sua composição maior concentração de farelo de soja e, portanto, maior teor de PB. Quanto ao consumo de extrato etéreo, este foi maior para os animais que receberam os suplementos SE e SP e menor para os animais controle (Tabela 4).

O consumo de carboidratos não-fibrosos (CNF) foi maior para os animais recebendo o suplemento $\mathrm{SE}(\mathrm{P}=0,0020)$ em decorrência da maior proporção de CNF no respectivo suplemento (Tabela 4). De forma geral a suplementação concentrada promoveu maior consumo de nutrientes digestíveis totais (NDT) $(\mathrm{P}=0,0106)$ pelos animais, visto que o teor de NDT é principalmente em função da proporção de CNF e PB dos suplementos.

Os diferentes suplementos promoveram alterações no coeficiente de digestibilidade aparente da MS, MO, PB, CT, CNF e NDT com exceção do coeficiente de digestibilidade aparente da FDN (Tabela 5). Os suplementos SE, SP e SM proporcionaram maior digestibilidade aparente da MS ( $\mathrm{P}=0,0004)$ e NDT $(\mathrm{P}<0,0001)$ em relação aos animais recebendo apenas $\mathrm{MM}$, o que comprova que o fornecimento de suplemento concentrado para bovinos em pastejo potencializa a digestão dos nutrientes da forragem.

Tabela 5. Coeficientes de digestibilidade aparentes totais de nutrientes $(\mathrm{g} / \mathrm{kg})$ em novilhas sob pastejo recebendo suplemento mineral (MM), energético (SE), proteico (SP) e múltiplo (SM) no período de transição seca-águas.

\begin{tabular}{lccccc}
\hline \multirow{2}{*}{ Variável } & \multicolumn{4}{c}{ Suplemento } & \multirow{2}{*}{ Valor P } \\
\cline { 2 - 5 } & MM & SE & SP & SM & \\
\hline Matéria seca total & $46,15 \pm 1,73^{\mathrm{b}}$ & $54,32 \pm 3,01^{\mathrm{a}}$ & $53,67 \pm 2,82^{\mathrm{a}}$ & $57,25 \pm 2,66^{\mathrm{a}}$ & 0,0010 \\
Matéria orgânica & $50,85 \pm 1,58^{\mathrm{c}}$ & $58,44 \pm 2,74^{\mathrm{b}}$ & $57,76 \pm 2,58^{\mathrm{b}}$ & $62,64 \pm 2,33^{\mathrm{a}}$ & 0,0004 \\
Proteína bruta & $35,30 \pm 2,07^{\mathrm{b}}$ & $37,58 \pm 3,57^{\mathrm{b}}$ & $59,69 \pm 1,51^{\mathrm{a}}$ & $59,12 \pm 2,31^{\mathrm{a}}$ & $<0,0001$ \\
Fibra em detergente neutro & $52,13 \pm 1,53$ & $51,93 \pm 3,54$ & $53,22 \pm 3,48$ & $55,23 \pm 3,02$ & 0,3004 \\
Carboidratos totais & $57,45 \pm 1,36^{\mathrm{b}}$ & $62,79 \pm 2,49^{\mathrm{a}}$ & $58,96 \pm 2,82^{\mathrm{b}}$ & $63,28 \pm 2,36^{\mathrm{a}}$ & 0,0108 \\
Carboidrato não-fibroso & $63,00 \pm 1,19^{\mathrm{c}}$ & $78,00 \pm 1,24^{\mathrm{a}}$ & $71,01 \pm 1,60^{\mathrm{b}}$ & $76,07 \pm 1,41^{\mathrm{a}}$ & $<0,0001$ \\
Nutrientes digestíveis totais & $46,12 \pm, 173^{\mathrm{b}}$ & $58,88 \pm 2,57^{\mathrm{a}}$ & $57,76 \pm 2,34^{\mathrm{a}}$ & $60,81 \pm 2,37^{\mathrm{a}}$ & $<0,0001$ \\
\hline
\end{tabular}

Valores seguidos de letras iguais na linha, não diferem pelo teste SNK a 5\% de probabilidade.

Fonte: Elaborado pelos autores.

A digestibilidade da $\mathrm{PB}$ foi maior para os animais suplementados com SP e SM em relação ao grupo SE e MM (Tabela 5), este fato foi devido os suplementos SP e SM apresentarem maior teor de PB em suas composições.

Quanto aos CTeCNF houve maior digestibilidade para os suplementos SE eSM.A maior digestibilidade de CNF dos animais que receberam os suplementos SE e SM pode ser atribuído ao maior teor de CNF nestes suplementos (Tabela 3), pois o teor de
CNF é superior no milho em relação ao farelo de soja, além disso, maior consumo de CNF para os correspondentes suplementos (Tabela 4) resultam em digestibilidade aparente (Tabela 5) mais alta, que segundo Van Soest (1994) é resultado da maior diluição na fração metabólica fecal.

Os animais apresentaram diferenças em relação às concentrações de nitrogênio amoniacal $\left(\mathrm{N}-\mathrm{NH}_{3}\right)$ ruminal, antes da suplementação (tempo zero) com os diferentes suplementos (Tabela 6). Os suplementos 
SM e SP proporcionaram maiores concentrações de $\mathrm{N}-\mathrm{NH}_{3}$ ruminal que os suplementos SE e MM.

Antes do fornecimento (tempo zero hora) pode-se verificar que todos os suplementos proporcionaram valores de $\mathrm{N}_{-} \mathrm{NH}_{3}$ ruminal acima do recomendado por Detmann, Paulino e Valadares Filho (2010) de $8 \mathrm{mg}$ de $\mathrm{N}-\mathrm{NH}_{3} / \mathrm{dL}$ de líquido ruminal considerados como mínimos para adequada fermentação ruminal da fibra. Contudo, deve-se considerar que $8 \mathrm{mg} /$ $\mathrm{dL} \mathrm{N}-\mathrm{NH}_{3}$ ruminal seriam suficientes para atender apenas os requisitos dos microrganismos fibrolíticos que utilizam o $\mathrm{N}-\mathrm{NH}_{3}$ ruminal como principal precursor para crescimento. Entretanto, para atender os requisitos do animal em proteína metabolizável a produção de compostos microbianos no rúmen deveria ser maximizada com valores de $15,33 \mathrm{mg} /$

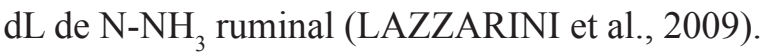

Tabela 6. Concentração de nitrogênio amoniacal $\left(\mathrm{N}^{-\mathrm{NH}_{3}}\right)$ ruminal antes $(0)$ e após 4 horas da suplementação e concentração de nitrogênio ureico no soro (NUS) de novilhas sob pastejo recebendo suplemento mineral (MM), energético (SE), proteico (SP) e múltiplo (SM) no período de transição seca-águas.

\begin{tabular}{|c|c|c|c|c|c|c|}
\hline \multirow{2}{*}{ Variável } & \multirow{2}{*}{ Hora } & \multicolumn{4}{|c|}{ Suplemento } & \multirow{2}{*}{ Valor P } \\
\hline & & MM & SE & $\mathrm{SP}$ & SM & \\
\hline \multirow{2}{*}{$\mathrm{N}-\mathrm{NH}_{3}(\mathrm{mg} / \mathrm{dL})$} & 0 & $8,17 \pm 0,37^{b}$ & $9,48 \pm 0,82^{\mathrm{ab}}$ & $11,55 \pm 0,92^{\mathrm{a}}$ & $11,77 \pm 0,80^{\mathrm{a}}$ & 0,0128 \\
\hline & 4 & $10,68 \pm 0,28^{\mathrm{c}}$ & $15,91 \pm 1,10^{\mathrm{b}}$ & $33,34 \pm 2,23^{\mathrm{a}}$ & $24,19 \pm 0,55^{\mathrm{a}}$ & $<0,0001$ \\
\hline NUS (mg/dL) & & $13,88 \pm 4,85$ & $19,25 \pm 4,90$ & $36,63 \pm 10,50$ & $26,25 \pm 6,87$ & 0,0698 \\
\hline
\end{tabular}

Valores seguidos de letras iguais na linha, não diferem pelo teste SNK a 5\% de probabilidade.

Fonte: Elaborado pelos autores.

Quatro horas após o fornecimento dos suplementos os animais recebendo os suplementos SP e SM proporcionaram maiores $(\mathrm{P}<0,0001)$ concentrações de $\mathrm{N}_{-} \mathrm{NH}_{3}$ (Tabela 6). Esses valores são superiores aos sugeridos por Sampaio et al. (2010) de $10 \mathrm{mg}$ de $\mathrm{N}-\mathrm{NH}_{3} / \mathrm{dL}$ de líquido ruminal em condições tropicais como ideais para a otimização da degradação ruminal e consumo voluntário.

Pode-se verificar que dos suplementos avaliados, o suplemento SE foi o que proporcionou menor concentração de $\mathrm{N}_{-} \mathrm{NH}_{3}$ ruminal (Tabela 6) e este fato pode ser justificado pela elevada proporção de milho neste suplemento (Tabela 1), uma vez que a degradabilidade ruminal da proteína do milho é menor que a do farelo de soja, bem como o fornecimento de CNF pode estimular o crescimento de bactérias que digerem este tipo de carboidrato, o que pode induzir ao aumento do uso do $\mathrm{N}$ no ambiente ruminal.
Apesar de ter havido diferenças no consumo de PB pelos animais, não foram observadas diferenças $(\mathrm{P}=0,0698)$ nos valores de nitrogênio uréico no soro (NUS) para as diferentes estratégias de suplementatação (Tabela 6).

Porto et al. (2009) relataram que níveis de uréia no sangue são afetados pelo nível nutricional, sendo este um indicador sensível e imediato da ingestão de proteína e utilização da amônia no rúmen, entretanto no presente estudo não foi observado alterações nas concentrações de NUS.

Valadares et al. (1997) ressaltaram que concentrações de NUS apresentam relação com o teor de PB da dieta (NUS $=-4,04+1,6295 \% \mathrm{~PB}$ ), e valores entre 13,52 e 15,15 mg/dL de NUS (11 a $12 \%$ de PB na dieta) provavelmente representariam limites a partir dos quais iniciaram as perdas de proteína dietética. 
Diante dos resultados obtidos para as concentrações de $\mathrm{N}_{-} \mathrm{NH}_{3}$ ruminal e NUS para os diferentes suplementos, pode-se verificar que os suplementos SP e SM proporcionaram melhor adequação do ambiente ruminal, desta forma, a escolha entre os suplementos deve levar em conta as variações de mercado para preços de aquisição de insumos, pois menores cotações de ingredientes podem elevar a lucratividade do sistema.

\section{Conclusões}

A utilização de suplementos energético, proteico e múltiplo para novilhas no período de transição seca-águas não alteram o consumo de matéria seca total e nitrogênio ureico no soro, entretanto proporcionam maior digestibilidade aparente total da matéria seca. Os suplementos proteico e múltiplo resultam em maior concentração de nitrogênio amoniacal no rúmen, resultando em melhor adequação do ambiente ruminal.

\section{Referências}

BARROS, L. V.; PAULINO, M. F.; MORAES, E. H. B. K.; DETMANN, E.; ALMEIDA, D. M.; MARTINS, L. S.; SILVA, A. G.; LOPES, S. A.; MÁRQUEZ, D. E. C.; CARDENAS, J. E. G. Desempenho produtivo e nutricional de novilhas de corte em pastejo suplementadas no período da seca e/ou no período de transição secaáguas. Semina: Ciências Agrárias, Londrina, v. 35, n. 4, p. 2655-2672, 2014. Suplemento 1.

CASALI, A. O.; DETMANN, E.; VALADARES FILHO, S. C.; PEREIRA, J. C.; HENRIQUES, L. T.; FREITAS, S. G.; PAULINO, M. F. Influência do tempo de incubação e do tamanho de partículas sobre os teores de compostos indigestíveis em alimentos e fezes bovina obtidos por procedimentos in situ. Revista Brasileira de Zootecnia, Viçosa, MG, v. 37, n. 2, p. 335-342, 2008.

COSTA, V. A. C.; DETMANN, E. VALADARES FILHO, S. C.; PAULINO, M. F.; HENRIQUES, L. T.; MANTOVANI, H. C. Degradação in vitro da fibra em detergente neutro de forragem tropical de alta qualidade em função da suplementação com proteína e/ou carboidratos. Revista Brasileira de Zootecnia, Viçosa, MG, v. 38, n. 9, p. 1803-1811, 2009.
DETMANN, E.; PAULINO, M. F.; VALADARES FILHO, S. C. Otimização do uso de recursos forrageiros basais. In: SIMPÓSIO DE PRODUÇÃO DE GADO DE CORTE. SIMCORTE, 7., 2010, Viçosa. Anais... Viçosa, MG: UFV, 2010. p. 191-240.

DETMANN, E.; QUEIROZ, A. C.; ZORZI, K.; MANTOVANI, H. C.; BAYÃO, G. F. V.; GOMES, M. P. C. Degradação in vitro da fibra em detergente neutro de forragem tropical de baixa qualidade em função da suplementação com proteína verdadeira e/ou nitrogênio não-proteico. Revista Brasileira de Zootecnia, Viçosa, MG, v. 40, n, 6, p.1272-1279, 2011.

HALL, M. B. Neutral detergent-soluble carbohydrates: nutritional relevance and analysis, a laboratory manual. Florida: University of Florida, 2000. 42 p. (Extension Bulletin, 339).

HERD, D. B. Mineral supplementation of beff cows in Texas. Texas: AgriLife Extension, 1997. Available at: $<\mathrm{http}$ :/animalscience-old.tamu.edu/beef-skillathon/pdf/ nutrition-mineral-supplementation.pdf $>$. Accessed at: 15 mar. 2012.

LAZZARINI, I.; DETAMANN, E.; SAMPAIO. C. B.; PAULINO, M. F.; VALADARES FILHO, S. C.; SOUZA, M. A.; OLIVEIRA, F. A. Intake and digestibility in cattle fed low-quality tropical forage and supplemented with nitrogenous compounds. Revista Brasileira de Zootecnia, Viçosa, MG, v. 38, n. 10, p. 2021-2030, 2009.

NATIONAL RESEARCH COUNCIL - NRC. Nutrients requirements of dairy cattle. $7^{\text {th }}$ ed. Washington: National Academy Press, 2001. 381 p.

PAULINO, M. F.; FIGUEIREDO, D. M.; MORAES, E. H. B. K.; PORTO, M. O.; SALES, M. F. L.; ACEDO, T. S.; VILLELA, S. D. J.; VALADARES FILHO, S. C. Suplementação de bovinos em pastagens: uma visão sistêmica. In: SYMPOSIUM OF BEEF CATTLE PRODUCTION, 4., 2004, Viçosa, MG. Anais... Viçosa, MG: Departamento de Zootecnia, UFV, 2004. p. 93144.

PORTO, M. O.; PAULINO, M. F.; VALADARES FILHO, S. C.; DETMANN, E.; SALES, M. F. L.; COUTO, V. R. M. Fontes de energia em suplementos múltiplos para bezerros Nelore em creepfeeding: desempenho produtivo, consumo e digestibilidade dos nutrientes. Revista Brasileira de Zootecnia, Viçosa, MG, v. 38, n. 7, p. 1329-1339, 2009.

SAMPAIO, C. B.; DETMANN, E.; PAULINO, M. F.; VALADARES FILHO, S. C.; SOUZA, M. A.; LAZZARINI, I.; PAULINO, P. V. R.; QUEIROZ, A. C. Intake and digestibility in cattle fed low-quality tropical 
forage and supplemented with nitrogenous compounds. Tropical Animal Health and Production, Edinburgh, v. 42, n. 6, p. 1471-1479, 2010.

SILVA, D. J.; QUEIROZ, A. C. Análise de alimentos: métodos químicos e biológicos. 3. ed. Viçosa, MG: Universidade Federal de Viçosa, 2002. 165 p.

SILVA-MARQUES，R. P.; ZERVOUDAKIS， J. T.; HATAMOTO-ZERVOUDAKIS, L. K.; CABRAL, L. S.; ALEXANDRINO, E.; JOSÉ NETO, A.; SOARES, J. Q.; MELO, A. C. B. Suplementos múltiplos para novilhas de corte a pasto no período seco: características nutricionais. Semina: Ciências Agrárias, Londrina, v. 36, n. 1, p. 509524, jan./fev. 2015a.

SILVA-MARQUES, R. P.; ZERVOUDAKIS， J. T.; HATAMOTO-ZERVOUDAKIS, L. K.; CABRAL, L. S.; ALEXANDRINO, E.; MELO, A. C. B.; SOARES, J. Q.; DONIDA, E. R.; SILVA, L. C. R. P. Suplementos múltiplos para novilhas de corte em pastejo no período seco. Semina: Ciências Agrárias, Londrina, v. 36, n. 1, p. 525-540, jan./fev. 2015b.

SNIFFEN, C. J.; O'CONNOR, J. D.; VAN SOEST, P. J.; FOX, D. G.; RUSSEL, J. B. A net carbohydrate and protein system for evaluating cattle diets: II. Carbohydrate and protein availability. Journal Animal Science, Madison, v. 70, n. 11, p. 3562-3577, 1992.
SAS - Statistical Analysis System. 1999. User's guide: statistics, version 8. Cary, NC: SAS Institute, 1999.

VALADARES, R. F. D.; BRODERICK, G. A.; VALADARES FILHO, S. C.; CLAYTON, M. K. Effect of replacing alfalfa silage with high moisture corn on ruminal protein synthesis estimated from excretion of total purine derivatives. Journal of Dairy Science, Madison, v. 82, n. 11, p. 2686-2696, 1999.

VALADARES, R. F. D.; GONÇALVES, L. C.; RODRIGUEZ. N. M.; VALADARES FILHO, S. C.; SAMPAIO, I. B. M. Níveis de proteína bruta em dietas de bovinos. 4. Concentração de amônia ruminal, uréia plasmática e excreções de creatinina. Revista Brasileira de Zootecnia, Viçosa, MG, v. 26, n. 6, p. 1270-1278, 1997.

VAN SOEST, P. J. Nutritional ecology of the ruminant. $2^{\text {th }}$ ed. Ithaca: CornelI University Press, 1994. $476 \mathrm{p}$.

VAN SOEST, P. J.; ROBERTSON, J. B.; LEWIS, B. A. Methods for dietary fiber, neutral detergent fiber, and nonstarch polyssacharides in relation to animal nutrition. Journal of Animal Science, Champaign, v. 74, n. 10, p. 3583-3597, 1991. 